\title{
Examining the Overlap Between ADHD and Autism Spectrum Disorder (ASD) Using Candidate Endophenotypes of ADHD
}

Salunkhe, G.; Weissbrodt, K.; Feige, B.; Saville, Christopher; Berger, A.; Dundon, N.M.; Bender, S.; Smyrnis, N.; Beauducel, A.; Biscaldi, M.; Klein, Christoph

\section{Journal of Attention Disorders}

DOI:

$10.1177 / 1087054718778114$

Published: 01/01/2021

Peer reviewed version

Cyswllt i'r cyhoeddiad / Link to publication

Dyfyniad o'r fersiwn a gyhoeddwyd / Citation for published version (APA):

Salunkhe, G., Weissbrodt, K., Feige, B., Saville, C., Berger, A., Dundon, N. M., Bender, S., Smyrnis, N., Beauducel, A., Biscaldi, M., \& Klein, C. (2021). Examining the Overlap Between ADHD and Autism Spectrum Disorder (ASD) Using Candidate Endophenotypes of ADHD. Journal of Attention Disorders, 25(2), 217-232. https://doi.org/10.1177/1087054718778114

\footnotetext{
Hawliau Cyffredinol / General rights

Copyright and moral rights for the publications made accessible in the public portal are retained by the authors and/or other copyright owners and it is a condition of accessing publications that users recognise and abide by the legal requirements associated with these rights.

- Users may download and print one copy of any publication from the public portal for the purpose of private study or research.

- You may not further distribute the material or use it for any profit-making activity or commercial gain

- You may freely distribute the URL identifying the publication in the public portal ?
}

Take down policy

If you believe that this document breaches copyright please contact us providing details, and we will remove access to the work immediately and investigate your claim. 


\section{Examining the overlap between Attention-Deficit Hyperactivity Disorder (ADHD) and Autism Spectrum Disorders (ASD) using candidate endophenotypes of ADHD}

Salunkhe, G. ${ }^{1}$ Weissbrodt, K. ${ }^{1}$, Feige, B. ${ }^{2}$, Saville, C.W.N. ${ }^{3}$, Berger, A. ${ }^{6}$, Dundon, N.M. ${ }^{1}$, Bender, S. ${ }^{4}$, Smyrnis, N. ${ }^{5}$, Beauducel, A. ${ }^{7}$, Biscaldi, M. ${ }^{1}$, Klein, C. ${ }^{1,4}$

\footnotetext{
${ }^{1}$ Department of Child and Adolescent Psychiatry, Psychotherapy, and Psychosomatics, Medical Faculty, University of Freiburg, Germany

${ }^{2}$ Department of Psychiatry and Psychotherapy, Medical Faculty, University of Freiburg, Germany

${ }^{3}$ School of Psychology, Bangor University, United Kingdom

${ }^{4}$ Department of Child and Adolescent Psychiatry, Medical Faculty, University of Cologne, Germany

${ }^{5}$ Department of Psychiatry, National and Kapodistrian University of Athens, Eginition Hospital, Greece

${ }^{6}$ Department of Psychology and Zlotowski Center for Neuroscience, Ben-Gurion University of the Negev, Beer Sheva, Israel

${ }^{7}$ Department for Research Methods, Diagnostics and Evaluation, Rheinische Friedrich-Wilhelms-Universität, Kaiser-Karl-Ring 9, 53111 Bonn, Germany
}

Address correspondence to:

Prof. Dr. Christoph Klein

Department of Child and Adolescent Psychiatry

Hauptstrasse 8

D - 79104 Freiburg

Phone: $++49-761-27068804$

FAX: $++49-761-27068590$

Email: christoph.klein.kjp@uniklinik-freiburg.de 


\begin{abstract}
Recent discussions of aetiological overlap between Attention Deficit Hyperactivity Disorder (ADHD) and Autism Spectrum Disorder (ASD) require comparative studying of these disorders. We examined performance of ASD patients with (ASD+) and without (ASD-) comorbid ADHD, ADHD patients and controls for selected putative endophenotypes of ADHD: Intra-Subject Variability (ISV) of reaction times, working memory (WM), inhibition and temporal processing. We found that patients with ADHD or ASD+, but not ASD-, had elevated ISV across the entire task battery and temporal processing deficits; and that none of the groups were impaired in WM or inhibition. High levels of ISV and generally poor performance in ASD+ patients were only partially due to additive effects of the pure disorders. Overall, we conclude that, within our limited but heterogeneous task battery, ISV and temporal processing deficits are most sensitive to ADHD symptomatology and that controlling for ADHD comorbidity is mandatory when assessing ISV in autism.
\end{abstract}

\title{
1. Introduction
}

Attention Deficit Hyperactivity Disorder (ADHD) is characterized by persistent inattentiveness, hyperactivity and impulsiveness. Autism Spectrum Disorder (ASD) is characterized by qualitative impairments in social communication and social interaction; and restrictive and repetitive patterns of behaviour, interests and activities (American Psychiatric Association [APA], 2013). Earlier diagnostic protocols did not allow a comorbid diagnosis of these symptomatically heterogeneous neurodevelopmental disorders since ADHD symptoms in ASD patients were assumed to reflect or even be caused by primary features of ASD itself (Reiersen \& Todd, 2008). However, this rationale has been challenged by a number of empirical observations including shared heritability (Rommelse, Franke, Geurts, Hartman \& Buitelaar, 2010), high co-occurrence of symptoms (Sinzig, Walter \& Doepfner, 2009) and increased incidence of one disorder in non-affected relatives of patients with the other disorder (van Steijn et al., 2012). These findings point to a probable overlap of aetiological factors underlying ADHD and ASD. The revised diagnostic guidelines of DSM-5 (APA, 2013) allow a comorbid diagnosis, but more research is required to understand the nature of the potential overlap of these psychiatric disorders after carefully accounting for comorbidity of ADHD and ASD (Rommelse, Geurts, Franke, Buitelaar \& Hartman, 2011). A promising approach to identify common underlying pathophysiology of psychiatric disorders is by examining overlapping endophenotypes or intermediate phenotypes. For a measure to be an endophenotype, it must be associated with the disorder in the population, be heritable, co-segregate within families, be state-independent 
and have increased incidence in non-affected family members of patients than in general population (Gottesman \& Gould, 2003).

A well-established abnormality and potential 'regulatory' endophenotype of ADHD is Intra-Subject Variability (ISV) of reaction times (RTs) (Castellanos et al., 2005; Klein, Wendling, Huettner, Ruder \& Peper, 2006; Kuntsi \& Klein, 2012). ISV, as investigated in the present study, describes the fluctuations in performance arising purely from within an organism when presented with the same stimulus in the same situation at two points in time (Type I variability) or with the sequence of responses potentially showing some pattern or order other than a monotonic function of time (Type II) (Fiske \& Rice, 1955). Increased ISV is one of the most consistent findings in children, adolescents and adults with ADHD (Kofler et al., 2013; Tamm et al., 2012). Unaffected twins, siblings or parents of ADHD children also have elevated ISV (Bidwell et al., 2007; Kuntsi \& Stevenson, 2001; Nigg, Blaskey, Stawicki \& Sachek, 2004) indicating fulfilment of the heritability and familiality criteria for an endophenotype. In addition, ISV has high retest-reliability (Flehming, Steinborn, Langner, Scholz \& Westhoff, 2007; Saville et al., 2011) and is consistent across sensory modalities (Saville et al., 2012). The clinical relevance of ISV is evident since it predicts symptoms of ADHD (Rucklidge \& Tannock, 2002) and behavioral indicators of inattention (Antonini et al., 2013; Kofler, Rapport \& Alderson, 2008). It is also found that elevated ISV in ADHD patients is reduced by (DeVito et al., 2009; Heiser et al., 2004; Teicher et al., 2004) and may even predict poor responsiveness to methylphenidate (Lee et al., 2009).

Recent research emphasizes on the need for more thorough investigation of RT distributions to describe the nature of increased ISV of RTs in ADHD. Typical RT distributions are a superposition of normal (Gaussian) and exponential (ex-Gaussian) distributions. Mu, sigma and tau represent the mean (mu) and standard deviation (sigma) of the Gaussian component and the mean and standard deviation of the exponential component (tau) of an RT distribution, respectively. Several studies found that increased tau, representing a higher number of particularly-slow responses, differentiates ADHD patients from controls (Buzy et al., 2009; Feige et al., 2013; Hervey et al., 2006; Leth-Steensen, King Elbaz \& Douglas, 2000), and may serve as an independent endophenotype for the disorder (Lin, Hwang-Gu \& Gau, 2015; Henriquez-Henriquez et al., 2015). One theory suggests that increased tau may reflect more lapses of attention which are related to poor suppression of the default-mode network (DMN) in ADHD patients (Fassbender et al., 2009; Sonuga-Barke \& Castellanos, 2007). Findings of a low-frequency spectral signature for tau which is overall similar to temporal characteristics of DMN-related interferences adds further evidence to support this theory (Feige et al., 2013). 
A recent meta-analysis has provided an inferential argument that elevated ISV in ASD patients may arise only when a comorbid ASD+ADHD group is included (Karalunas et al., 2014), but there is inconsistency to this suggestion since Geurts et al. (2008) found elevated ISV both in patients with pure ASD patients and in ASD patients with comorbid ADHD, but not in ADHD patients. Moreover, recent studies of ISV that did consider for comorbidity of ADHD in ASD patients only examined performance in individual tasks rather than task batteries (Lundervold et al., 2012; Adamo et al., 2014; Tye et al., 2016), leaving it unresolved whether elevated levels of ISV, if present in these patients, remain consistently elevated across cognitively heterogeneous tasks and thus potentially represent a unitary underlying process (Klein et al., 2006; Saville et al., 2012) rather than a taskspecific abnormality.

Increased ISV, however, is not the only endophenotype candidate of ADHD. Other frequently-studied candidate endophenotypes of a more cognitive nature include working memory (WM), inhibition and temporal processing. Deficits have been consistently found in ADHD patients for WM (Kasper, Alderson \& Hudec, 2012; Martinussen, Hayden, Hogg-Johnson \& Tannock, 2005; Sowerby, Seal \& Tripp, 2011), inhibition (Alderson, Rapport \& Kofler, 2007; Lijffijt, Leon, Verbaten \& van Engeland, 2005; Suskauer et al., 2008; Wodka et al., 2007) and temporal processing (Toplak, Dockstadter \& Tannock, 2006; Noreika, Falter \& Rubia, 2013; Rommelse, Oosterlaan, Buitelaar, Faraone \& Sergeant, 2007). Results for ASD patients, by contrast, are overall less clear (Happé, Booth, Charlton \& Hughes, 2006; Sinzig, Morsch, Bruning, Schmidt \& Lehmkuhl, 2008; Goldberg et al., 2005; Verté, Geurts, Roeyers, Oosterlaan, \& Sergeant, 2006; Corbett, Constantine, Hendren, Rocke \& Ozonoff, 2009; Mahone et al., 2006; Bhatara, Babikian, Laugeson, Tachdijian \& Sininger, 2013; Falter, Noreika, Wearrden \& Bailey, 2012; Gil, Chambres, Hyvert, Fanget \& Droit-Volet, 2012; Wallace \& Happé, 2008). Conflicting results for ASD patients may be related to the issue that most previous studies did not consider for comorbid ADHD in their samples of ASD patients. It is as such crucial that the performance of comorbid patients is examined independently from the pure disorders to determine the nature of a potential overlap of ASD and ADHD.

The present study is a follow-up to Biscaldi et al. (2016) in which ISV was found to be inconsistently elevated across a range of tasks probing heterogeneous cognitive dimensions in comorbid ASD+ADHD patients but not pure ASD patients. One major shortcoming of this study was the lack of comparison of performance with ADHD patients. The current study examined performance in a larger sample of age- and IQ-matched ASD patients (with and without comorbid ADHD) and controls; and also in an additional sample of ADHD patients. The main aims were to examine whether: firstly, ISV is elevated in ASD patients; secondly, levels of ISV in ASD 
patients, if elevated, remain consistent across cognitively heterogeneous tasks (N-Back task, a Stop Signal Task and a Time Reproduction Task); thirdly, ASD patients have deficits related to the selected candidate cognitive endophenotypes of ADHD (WM, inhibition, temporal processing); and fourthly, deficits in comorbid patients are driven by additive effects of the two pure disorders.

\section{Methods}

All procedures were approved by the ethics committee of the University of Freiburg. Signed informed consent was obtained from all the participants and their parents before their participation in the study.

$* * * * * * * * * * * * * * * * * * * * * * * * * * * * * * * * * * *$ insert Table 1 about here

\subsection{Participants}

The data of 40 ADHD patients, 21 ASD patients (ASD-), 19 ASD patients with comorbid ADHD (ASD+) and 40 typically developing (TD) controls was available for statistical analyses. The exclusion criteria for the study were severe comorbid neurological or psychiatric disorders (including of Tourette syndrome) and/or intellectual disability (full scale IQ below 70). Groups were matched for sex, age and IQ (see Table 1 for demographic and psychometric details).

Controls were recruited from local schools and sports groups. They had no known psychiatric or neurological history which was confirmed in advance via telephone screening with the parents of the children. In particular, symptoms of ADHD and ASD were excluded using the parent-rated Child Behaviour Checklist (CBCL; Achenbach \& Rescorala, 2001) and Social Responsiveness Scale (SRS; Bölte \& Poustka, 2007) as screening instruments for participants of all the groups.

All patients were recruited at the outpatient clinic of the Department of Child and Adolescent Psychiatry and Psychotherapy in Freiburg. For the ADHD group, diagnoses were made according to the ICD-10 criteria and were based on anamnestic interviews with children and their parents, the German version of the Conner's parents and teacher-rating scales and systematic behavioural observations in a simulated classroom setting. Additionally, a semi-structured diagnostic interview, the K-SADS-PL (Kaufman, Birmaher, Brent, Rao \& Ryan, 2001) was administered in its German adaptation, separately to the children and their parents to screen for comorbid disorders. These interviews confirmed that nineteen of the children included in the ADHD group had comorbid diagnoses, namely, expressive language disorder $(\mathrm{N}=2)$, specific reading disorder $(\mathrm{N}=2)$, disorder of 
written expression $(\mathrm{N}=2)$, dyscalculia $(\mathrm{N}=1)$, unspecified anxiety disorder $(\mathrm{N}=1)$, adjustment disorders $(\mathrm{N}=7)$, specific developmental disorder of motor coordination $(\mathrm{N}=4)$, non-organic enuresis $(\mathrm{N}=4)$ and encopresis $(\mathrm{N}=1)$.

For patients with ASD, diagnoses were made according to the ICD-10 and DSM-IV-TR criteria and further confirmed based on the German version of the standardised Autism Diagnostic Observation Schedule (ADOS; Rühl, Bölte, Feineis-Matthews \& Poustka, 2004) and semi-structured Autism Diagnostic Interview (ADIR; Bölte, Rühl, Schmötzer \& Poustka, 2005). According to the German adaptation of the K-SADS-PL diagnostic interview (Kaufman et al., 2001), which was administered separately to the children and their parents, 19 children within this group had comorbid ADHD (ASD+) due to symptoms related to all three scales; inattention, hyperactivity and impulsiveness. Other comorbidities for children included in the ASD group that were also assessed using the K-SADS-PL interview were expressive language disorder $(\mathrm{N}=1)$, specific reading disorder $(\mathrm{N}=5)$, separation anxiety $(\mathrm{N}=1)$, adjustment disorders $(\mathrm{N}=2)$, specific isolated phobias $(\mathrm{N}=1)$, specific development disorder of motor coordination $(\mathrm{N}=2)$, non-organic enuresis $(\mathrm{N}=3)$ and encopresis $(\mathrm{N}=3)$, mixed obsessive thoughts and acts $(\mathrm{N}=1)$, mild depressive episode $(\mathrm{N}=1)$ and simple vocal or motor tics disorder $(\mathrm{N}=5)$. Symptoms of ADHD in the clinical groups were finally additionally verified by the results of the Germanadapted questionnaires DISYPS ${ }^{1}$ (FBB-ADHD) (Döpfner, Görtz-Dorten, Lehmkuhl, Breuer \& Goletz, 2008) and CBCL (Achenbach \& Rescorla, 2001). Sixteen ASD patients and twenty four ADHD patients had a methylphenidate prescription but did not take the medication at least twenty four hours prior to the testing.

\subsection{Hardware, tasks and procedures}

All experiments were designed on the 'E-Prime 2.0 Professional' software (Schneider, Eschmann \& Zuccolotto) and presented to the children using 17-inch monitors. Experimenters gave the children verbal instructions aided by schematic drawings to describe the task, which was followed by 10-20 practice trials.

In the N-Back Task (NBT) participants were instructed to respond to all trials; with one key for infrequent 'target' trials and another key for frequent 'non-target' trials. The NBT consisted of two levels: 0Back Task (0BT) and 1-Back Task (1BT). Each task level comprised of a total of 208 trials; wherein $25 \%$ of the trials were targets and the remainder were non-targets. A white letter was presented at the centre of the screen every $2 \mathrm{~s}$ for duration of $0.5 \mathrm{~s}$ and followed by a black screen. In the $0 \mathrm{BT}$, the letter ' $\mathrm{X}$ ' was defined as the target and any other letter was a non-target. In the 1BT, a letter was defined as a target only if the preceding letter was

\footnotetext{
${ }^{1}$ clinical cut-off: sub-scale and total scores $<=1$
} 
identical to it; else it was defined as a non-target. Participants were instructed to respond as quickly and accurately as possible. RT data was recorded for responses between 0 and $1500 \mathrm{~ms}$ after stimulus presentation.

The Stop Signal Task (SST) consisted of a total of 400 trials; $25 \%$ of which were 'STOP' trials and the remainder were 'GO' trials. The letters ' $\mathrm{L}$ ' and ' $\mathrm{R}$ ' were presented randomly and at an equal likelihood at the centre of the screen, in a similar fashion as in the NBT. For the ' $L$ ' and 'R' trials, participants were instructed to press the left or right response buttons respectively. In 'STOP' trials, a red 'STOP' stimulus appeared after a 'GO' trial and remained on the screen for a duration of $25 \mathrm{~ms}$, wherein participants were instructed to inhibit their responses. The first 'STOP' stimulus appeared 150ms after the letter, but a tracking algorithm increased the stopsignal delay by $25 \mathrm{~ms}$ if participants successfully inhibited their responses and decreased it by $25 \mathrm{~ms}$ in case of a commission, thus converging at an inhibition likelihood of around 50\%. RT data was recorded for responses between 0 and $1650 \mathrm{~ms}$ after stimulus presentation.

In the Time Reproduction Task (TRT), a white circle was displayed on a black screen for a duration of $1,2,4,8$ or 16s. Fifteen trials for each of the durations were presented in random order. Participants were instructed to reproduce this duration by pressing a button that allows a blue circle to both appear and disappear.

In a second session, the Standard Progressive Matrices (R-SPM; Raven \& Horn, 2009) for measurement of IQ and three other computerized reaction time (RT) tasks were administered; the results for these tasks will be reported elsewhere.

\subsection{Data Analysis}

\subsubsection{Definition of parameters}

Previous studies have examined ISV of RTs lying within the range of 200-1500ms (Feige et al., 2013; Biscaldi et al., 2016). In the present study, a novel data-driven classification was used to statistically identify and exclude very early RTs which are likely to be anticipations in the speeded RT tasks (NBT, SST). Chi-squared tests were used to compare the total number of correct responses vs. incorrect responses in bins of width $25 \mathrm{~ms}$, separately for each of the groups. Bin-wise comparisons revealed that a similar proportions of correct and incorrect responses produced non-significant chi-squared results when RTs were below 250ms and that responses were significantly more likely to be correct rather than incorrect only when RTs were 250ms and above $(p<.05)$. Accordingly, RT-performance variables were computed for correct responses with latencies of 250ms and above (see Figure 1.1). A maximum cut-off was set at $1500 \mathrm{~ms}$ for both tasks. 
Next, RTs of speeded RT tasks (NBT, SST) were 'residualised' by subtracting the fit to linear models for the significant Type I ISV effect of time-on-task (e.g. fatigue, practice effects, sustained attention) (NBT: $F(1,41013)=9.95, p=.002$; SST: $F(1,25748)=138.06, p<.001)$, the Type III ISV effect (that is, effects of varying task or stimulus conditions) of TRIALTYPE (NBT: $F(1,117)=31.75, p<.001)$, the interaction effect of TRIALTYPE with post-error and post-omission slowing of RTs (NBT: $F(2,384)=3.88, p=.021)$ and the effect of post-'STOP' signal slowing of RTs (SST: $F(2,238)=24.49, p<.001)$. This procedure was performed to "extract" Type I (except time-on-task) and II variability arising endogenously.

For the NBT and the SST, measures of variability (RTSD, sigma, tau), accuracy (incorrect responses, omission errors) and speed (mean RTs, mu) were examined. Mu, sigma and tau parameters (see Introduction) were derived by the ex-Gaussian analysis which was done using the Quantile Maximum Probability Estimation programme (QMPE v2.18) (Cousineau, Brown \& Heathcote, 2004) and GAMLSS package (Stasinopoulos \& Rigby, 2007). For the SST, the following measures were computed to additionally examine inhibitory processing: Stop Signal Delay is the time between the onset of the 'GO' signal and the onset of the 'STOP' signal as timed by the tracking algorithm; Stop Reaction Time refers to the speed of non-inhibited responses following the 'STOP' signal; Stop Signal Reaction Time is the time to suppress a response for 'STOP' trials adjusted for the mean RT in ‘GO’ trials.

For the TRT, since there was no time limit for the reproductions, for each interval separately, reproduced intervals lying 3 standard deviations above or below that of their (sub) group's threshold were winsorized by replacing them with the corresponding value of the lower or upper threshold respectively. Subsequently, the following measures of temporal error and its variability were examined: Relativized Absolute Discrepancy Score is the absolute degree of reproduction error divided by the corresponding interval; Coefficient of Accuracy refers to the estimated time divided by the corresponding interval and reflects the degree of over$(>1)$ or underestimation $(<1)$; Standard Deviation of the Reproduced Intervals is the deviation from the mean reproduced time of each interval divided by the corresponding interval.

In addition to the analyses for individual tasks, the uniformity of the degree of group differences for ISV across the cognitively heterogeneous tasks (in terms of effect sizes) was statistically investigated. For this analysis, the TASK x GROUP interaction was examined for ISV scores that were z-transformed task-wise (NBT, SST and TRT) across the participants of all groups.

\subsubsection{Statistics}


We ran linear mixed model ANOVAs using both centred-age and centred-IQ ('IQ ${ }^{\text {in') }}$ ) or only centred-age but not centred-IQ ('IQ ${ }^{\text {out'}}$ ) as covariates, given the debate regarding the appropriateness of controlling IQ in studies of neurodevelopmental disorders (Dennis et al., 2009). Within-subject factors were LOAD (0BT, 1BT) and TRIALTYPE (targets, non-targets) for the NBT; and INTERVAL $(1,2,4,8,16 \mathrm{~s})$ for the TRT. There was no within-subject factor for the SST. In the additional ANOVA with z-transformed ISV scores, TASK (NBT, SST and TRT) was a within-subjects factor. Between-subject factor of GROUP (Controls, ADHD, ASD+, and ASD-) and pairwise comparisons with Tukey adjusted $p$-values for multiple comparisons were used to examine whether deficits related to ADHD were also found in ASD patients. In supplementary ANOVAs, the between-subject factor was DIAGNOSTIC STATUS or "DS" (ASD-DS: ASD-/ASD+ vs. Controls/ADHD; ADHD-DS: ADHD/ASD+ vs. Controls/ASD-) where the main effect of DS and the interaction of ASD-DS x ADHD-DS were assessed. If significant main effects of diagnostic status are given, a non-significant ASD-DS x ADHD-DS interaction is consistent with an additive effect of the pure disorders on the ASD+ group, whereas a significant ASD-DS $\mathrm{x}$ ADHD-DS interaction indicates a non-additive effect of the pure disorders on the ASD+ group.

All ANOVAs were derived using the linear mixed-effects function ('anova.lme') of the non-linear mixed effects ('nlme') package (Pinheiro, Bates, DebRoy, Sarkar \& R Core Team, 2015) wherein effects were estimated using maximum likelihood and unstructured within-group correlations. All statistical analyses were done using 'RStudio'(R Core Team, 2013).

\section{Results}

Figures 1.1 and Figure 1.2 show the RT distributions for the NBT and the SST for all four groups (Controls, ADHD, ASD-, ASD+) and Table 2 shows the group-wise descriptive statistics for performance variables.

$* * * * * * * * * * * * * * * * * * * * * * * * * * * * * * * * * *$ insert Figures 1.1 about here $* * * * * * * * * * * * * * * * * * * * * * * * * * * * * * *$

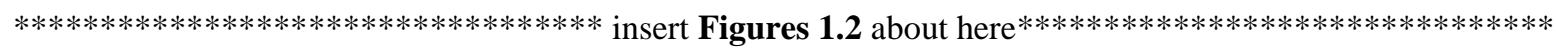

************************************** insert Table 2 about here $* * * * * * * * * * * * * * * * * * * * * * * * * * * * * * * * * *$

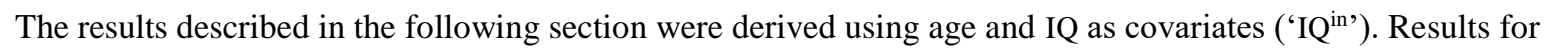
'IQ ${ }^{\text {out}, ~(o v e r a l l ~ s i m i l a r ~ t o ~ I Q ~}{ }^{\text {in }}$ results), are also available in Table A1 in the supplementary material. 


\subsection{Is ISV elevated in ASD patients?}

The main effects of GROUP for RTSD represented elevated variability in ADHD patients compared to controls and in ASD+ patients compared to all other groups for the NBT; and increased variability in only ASD+ patients compared to controls for the SST (see Table 3). For the TRT, a main effect of GROUP for the standard deviation of reproduced intervals reflected greater variability in ADHD patients compared to controls and in ASD+ patients compared to controls and ASD- patients (see Table 3), and a subsequent GROUP x INTERVAL interaction $(F(12,464)=3.23, p<.001)$ indicated that these group differences reached significance only for short intervals of 1s (ADHD vs. controls: $t(114)=5.91, p<.001, d=1.11$; ASD+ vs. controls: $t(114)=6.47, p<.001$, $d=1.21$; ASD+ vs. ASD- patients: $t(114)=4.02, p=.014, d=0.75$ ) or $2 \mathrm{~s}$ (ASD+ vs. controls: $t(114)=3.80, p=.030$, $d=0.71$; but not for $4 \mathrm{~s}(t<3.45 ; p>.084), 8 \mathrm{~s}(t<2.28 ; p>.746)$ and $16 \mathrm{~s}(t<1.33 ; p>.998)$ (see Figure 2c).

Significant task-related main effects were also present for the $\mathrm{NBT}^{2}$ and $\mathrm{TRT}^{3}$.

************************************ insert Table 3 about here $* * * * * * * * * * * * * * * * * * * * * * * * * * * * * * * * * *$

The ex-Gaussian measures of ISV were examined for the speeded RT tasks. For sigma, the main effect of GROUP was significant only for NBT (NBT: $F(3,114)=10.58, p<.001$; SST: $F(3,114)=1.76, p=.159)$ reflecting significantly higher sigma in only ASD+ patients compared to all other groups (ASD+ vs. controls: $t(1,114)=5.49$, $p<.001, d=1.03$; ASD+ vs. ASD-: $t(1,114)=3.76, p=.002, d=0.70$; ASD+ vs. ADHD: $t(1,114)=4.14, p<.001$, $d=0.78)$. For tau, the main effects of GROUP for the NBT $(F(3,114)=4.44, p=.006)$ and the SST $(F(3,114)=2.87$, $p=.040$ ) represented significantly and marginally higher tau in ASD+ patients compared to controls, respectively (NBT: $t(1,114)=3.43, p=.005, d=0.64$; SST $t(1,114)=2.33, p=.097, d=0.44)$. Tau was also elevated in ADHD patients in both tasks $(t>2.72 ; p<.004$; one-sided test). For tau in the NBT, the interactions of LOAD x GROUP (see section 3.3.1) and TRIALTYPE $\mathrm{x}$ GROUP $(F(3,232)=4.55, p=.004)$ were also significant. The TRIALTYPE $\mathrm{x}$ GROUP interaction reflected significantly elevated tau in ASD+ patients compared to controls for non-target trials only (non-targets: $t(114)=4.82, p<.001, d=0.90$; targets: $t(114)=0.86, p=.989, d=0.16)$. Significant main effects of

\footnotetext{
${ }^{2}$ RTSD/LOAD: $F(1,116)=66.06, p<.001 ; 0 \mathrm{BT}<1 \mathrm{BT}$

${ }^{3} \mathrm{SD}$ of reproduced intervals/INTERVAL: $F(4,464)=121.49, p<.001$; short intervals $>$ long intervals
} 
task were also found for the ex-Gaussian measures of ISV $\left(\operatorname{sigma}^{4,5}, \operatorname{tau}^{6,7}\right)$. Our first research question can thus be answered: ISV is elevated in ADHD patients and even more so in ASD+ patients, but not in ASD-patients.

3.2 Are the levels of ISV consistent across cognitively heterogeneous tasks in ASD patients?

In the additional ANOVA with z-transformed RTSD scores for the NBT and SST and standard deviation scores for reproduced intervals of the TRT, a main effect of $\operatorname{GROUP}(F(3,114)=13.78, p<.001)$ reflected significantly elevated ISV in ADHD patients compared to controls $(t(1,114)=3.98, p<.001, d=0.75)$ and in ASD+ patients compared to all other groups (ASD+ vs. controls: $t(1,114)=6.88, p<.001, d=1.29$; ASD+ vs. ASD-: $t(1,114)=4.27, p<.001, d=0.80 ;$ ASD + vs. ADHD: $t(1,114)=3.71, p=.002, d=0.70)$. A non-significant TASK x GROUP interaction $(F(6,232)=1.25, p=.283)$ confirmed that the patterns of increased ISV in the ADHD-related groups were consistent across the cognitively heterogeneous tasks.

3.3 Are deficits related to the selected candidate cognitive endophenotypes of ADHD also present in ASD?

\subsubsection{Working Memory (WM)}

In the NBT, a significant interaction of LOAD x GROUP, representing altered WM performance, was found for tau $(F(3,116)=4.51, p=.005)$ due to elevated scores in ASD+ patients compared to controls for the 0BT only (0BT: $t(114)=4.91, p<.001, d=0.92 ; 1 \mathrm{BT}(t(114)=0.55, p=.999, d=0.10)$. A significant LOAD x GROUP was also present for omission errors $(F(3,116)=3.50, p=.018)$ reflecting more omitted responses by ASD+ patients than all other groups for the 1BT (ASD+ vs. controls: $t(1,114)=5.97, p<.001, d=1.19$; ASD+ vs. ASD-: $t(1,114)=4.21, p=.001, d=0.79$; ASD+ vs. ADHD: $t(1,114)=5.08, p<.001, d=0.95)$ but not for the 0BT (ASD+ vs. controls: $t(1,114)=2.92, p=.077, d=0.55$; ASD+ vs. ASD-: $t(1,114)=2.07, p=.439, d=0.39$; ASD+ vs. ADHD: $t(1,114)=2.32, p=.290, d=0.43)$. Corresponding pairwise comparisons were overall non-significant for ADHD and ASD- indicating that the pure disorders performed similar to the controls when WM load was increased. LOAD $\mathrm{x}$ GROUP interactions were non-significant for all other measures, including RTSD, sigma, incorrect responses

\footnotetext{
${ }^{4}$ SIGMA/LOAD: $F(1,116)=14.62, p<.001 ; 0 \mathrm{BT}<1 \mathrm{BT}$

${ }^{5}$ SIGMA/TRIALTYPE: $F(1,232)=49.68, p<.001$; target trials $>$ non-target trials

6 TAU/LOAD: $F(1,116)=6.81, p=.010 ; 0 \mathrm{BT}<1 \mathrm{BT}$

7 TAU/TRIALTYPE: $F(1,232)=89.73, p<.001$; target trials $<$ non-target trials
} 
mean RTs and $\mathrm{mu}(F<1.76 ; p>.158)$. While the increase in WM load did not differentiate the pure disorders from controls, disproportionate alterations in tau and omission errors were found in ASD+ patients.

\subsubsection{Inhibition}

In the SST, the accuracy of correctly inhibited responses was about $50 \%$ in all groups as expected according to the tracking algorithm (see Table 2). Group differences for measures of inhibitory processing (Stop Signal Delay: $F(3,114)=2.12, p=.101$; Stop Reaction Time: $F(3,114)=2.38, p=.073$; Stop Signal Reaction Time: $F(3,114)=2.11, p=.103)$, measures of overall speed (mean RTs: $F(3,114)=2.13, p=.101)$ or Gaussian speed $(\mathrm{mu}$ : $F(3,114)=1.51, p=.215)$ in the SST did not reach significance. However, the significant main effects of GROUP for incorrect responses $(F(3,114)=3.21, p=.026)$ and omission errors $(F(3,114)=3.26, p=.024)$ reflected that ADHD patients made significantly more incorrect responses than controls $(t(1,114)=2.88, p=.024, d=0.54)$ and that ASD+ patients had significantly more omissions than controls $(t(1,114)=2.99, p=.018, d=0.56)$ respectively. Overall, no deficits related to inhibitory processing were found in any of the groups.

\subsubsection{Temporal processing}

In the TRT, a main effect of GROUP for Relativized Absolute Discrepancy Scores $(F(3,114)=4.54$, $p=.005)$ represented significantly higher reproduction error in $\mathrm{ASD}+(t(1,114)=3.33, p=.006, d=0.62)$ and $\mathrm{ADHD}$ patients $(t(1,114)=2.62, p=.048, d=0.49)$ compared to controls (also see Figure 2a). Groups did not significantly differ for Coefficient of Accuracy $(F(3,114)=0.49, p=.689)$; but a significant GROUP $\mathrm{x}$ INTERVAL interaction $(F(12,464)=2.16, p=.013)$ reflected a larger main effect of INTERVAL in ADHD patients $(F(4,156)=35.66$, $p<.001)$ and ASD+ patients $(F(4,72)=20.73, p<.001)$ than in controls $(F(4,156)=17.31, p<.001)$ and ASD- patients $(F(4,80)=10.34, p<.001)$ due to greater overestimations for shorter intervals and greater underestimations for longer intervals (Figure 2b). The main effects of INTERVAL were also significant for Relativized Absolute Discrepancy Scores ${ }^{8}$ and Coefficient of Accuracy ${ }^{9}$. Temporal processing was thus impaired in ADHD and ASD+, but not in ASD- patients.

$* * * * * * * * * * * * * * * * * * * * * * * * * * * * * * * *$ insert Figure 2 about here $* * * * * * * * * * * * * * * * * * * * * * * * * * * * * * * * * *$

\footnotetext{
${ }^{8}$ Relativized Absolute Discrepancy Score: $F(4,464)=56.70, p<.001$; short intervals > long intervals

${ }^{9}$ Coefficient of Accuracy: $F(4,464)=77.19, p<.001$; overestimation for short intervals and underestimation for long intervals
} 
The inferential statistics for interaction and main effects described in this section are found in Table 4.

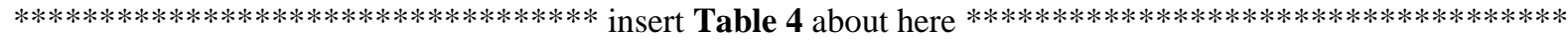

The interactions of ASD-DS x ADHD-DS were significant for sigma, omission errors and mu of the NBT (GROUP-wise results for measures of accuracy and speed in the NBT in section 3.5), suggesting non-additive effects of the pure disorders on the ASD+ group for these measures. The lower order main effects for these NBTmeasures indicate that sigma and omission errors were significantly elevated by ADHD symptomatology (ADHDDS) and even more so by autism symptomatology (ASD-DS); but mu was significantly elevated by autistic symptomatology alone. For all the other measures, ASD-DS x ADHD-DS interaction effects were not significant although some showed a trend in that direction (Table 4). As such, deficits in ASD+ patients arise from a combination of both additive and non-additive effects of the pure disorders, depending on the variable under scrutiny.

\subsection{Additional results}

Measures of accuracy and speed were also examined in the NBT. A TRIALTYPE x GROUP interaction $(F(3,232)=2.68, p=.048$; GROUP: $F(3,114)=2.80, p=.043)$ reflected more errors in ADHD patients than controls for target trials only (targets: $t(114)=3.21, p=.036, d=0.60$; non-target trials $t(114)=-1.78, p=.638, d=0.33$ ). A TRIALTYPE x GROUP interaction $(F(3,232)=14.27, p<.001$; GROUP: $F(3,114)=9.56, p<.001)$ for omission errors reflected that ASD+ patients omitted more responses than controls $(t(1,114)=7.41, p<.001, d=1.39)$, ASD- patients $(t(1,114)=5.40, p<.001, d=1.01)$ and ADHD patients $(t(1,114)=6.14, p<.001, d=1.15)$ following non-target trials

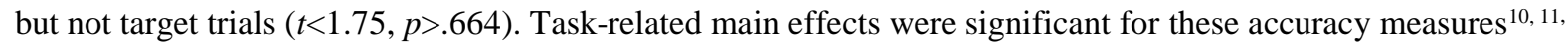
12, 13. Regarding response speed, the main effects of GROUP were significant for both mean RTs $(F(3,114)=6.18$, $p=.001)$ and $\mathrm{mu}(F(3,114)=3.68, p=.014)$ reflecting significantly longer mean RTs for ASD+ patients compared to all groups (ASD+ vs. controls: $t(1,114)=4.17, p<.001, d=0.78$; ASD+ vs. ASD-: $t(1,114)=2.75, p=.034, d=0.52$; ASD+ vs. ADHD: $t(1,114)=3.34, p=.006, d=0.63)$ and significantly higher mu in ASD+ patients compared to

\footnotetext{
10 incorrect responses/LOAD: $F(1,116)=128.26, p<.001 ; 0 \mathrm{BT}<1 \mathrm{BT}$

11 incorrect responses/TRIALTYPE: $F(1,232)=549.16, p<.001$; target trials $>$ non-target trials

12 omission errors/LOAD: $F(1,116)=20.79, p<.001$; $0 \mathrm{BT}<1 \mathrm{BT}$

13 omission errors/TRIALTYPE: $F(1,232)=100.59, p<.001$; target trials < non-target trials
} 
controls $(t(1,114)=2.97, p=.019, d=0.56)$ or ADHD patients $(t(1,114)=2.97, p=.018, d=0.56)$, respectively. The main effects of LOAD and TRIALTYPE were significant for mean RTs ${ }^{14,15}$ and $\mathrm{mu}^{16,17}$.

\section{Discussion}

The present study examined performance of patients with ADHD, ASD with (ASD+) or without comorbid ADHD (ASD-) and controls across a fairly heterogeneous battery of tasks related to selected putative endophenotypes of ADHD, namely ISV, working memory (WM) in the N-Back Task (NBT), inhibition in the Stop-Signal Task (SST) and temporal processing in the Time-Reproduction Task (TRT). Based on the main aims we found that, firstly, ISV was elevated in ADHD patients and even more so in comorbid ASD+ patients, but not in "pure" ASD- patients; secondly, levels of elevated ADHD-related ISV were uniform across the cognitively divergent tasks; and thirdly, none of the groups had deficits related to WM or inhibition but temporal processing deficits were present in both ADHD and ASD+ patients. Finally, highest levels of ISV and overall least favorable performance in ASD+ patients could only partially be explained by interaction effects of the pure disorders. In the following sections we will discuss these main findings.

\subsection{Is ISV elevated in ASD?}

ISV was the best predictor for group differences in the NBT and TRT, but group differences were less pronounced in the SST which may be linked to the poor reliability of this paradigm (Wöstmann et al., 2013). The general pattern of results suggests that ISV was elevated in ADHD patients and even more so in ASD+ patients, but not in ASD- patients, which is overall in line with recent literature (Adamo et al., 2014; Lundervold et al., 2012; Tye et al., 2016). In evaluating normal ISV in our "purely" autistic patients, it is important to emphasize that the ASD group as a whole (that is, the merged ASD- and ASD+ groups) did express significantly increased ISV in all tasks used here with medium to large effect sizes (RTSD: $3.38 \leq t \leq 4.83 ; 0.63 \leq d \leq .90 ; p s<.01$ ). Our results thus underline the importance of systematic consideration of ADHD comorbidity in studying autism in order to avoid misleading results, at least regarding ISV. Furthermore, our findings of elevated ISV in patients

\footnotetext{
14 Mean RTs/LOAD: $F(1,116)=46.90, p<.001$; 0BT <1BT

15 Mean RTs/TRIALTYPE: $F(1,116)=46.90, p<.001$; target trials $>$ non-target trials

${ }^{16} \mathrm{Mu} / \mathrm{LOAD}: F(1,116)=10.98, p=.001 ; 0 \mathrm{BT}<1 \mathrm{BT}$

${ }^{17} \mathrm{Mu}$ /TRIALTYPE: $F(1,232)=202.67, p<.001$; target trials $>$ non-target trials
} 
with ADHD symptoms irrespective of existing diagnostic criteria add further support to the recent notion that increased ISV may be a potential trans-diagnostic phenotype for ADHD (Karalunas et al., 2014; Nolen-Hoeksema \& Watkins, 2011). It is also noteworthy that the ADHD-related groups shared similar patterns for ISV with greater overall RTSD in the NBT and greater variability in reproducing short, but not long intervals in the TRT. ISV scores of the speeded-NBT did not share a greater degree of association with the ISV of short intervals (1s: $.200 \leq r \leq .344$; $2 \mathrm{~s}: .064 \leq r \leq .507)$ than with long intervals (4s: $.178 \leq r \leq .714 ; 8 \mathrm{~s}:-.062 \leq r \leq .352 ; 16 \mathrm{~s}: .055 \leq r$ $\leq .251$ ) of the TRT in any of the groups; thus our results provide only rather "patchy" support for the proposal that higher ISV is linked with deficits in temporal processing (Castellanos \& Tannock, 2002).

Intriguingly, for the speeded RT tasks, the ex-Gaussian measures highlight important differences between ADHD-related groups which are apparently masked by the global ISV-measure, RTSD. For ASD+ patients, both sigma and tau were significantly elevated in the NBT, confirming results of Geurts et al. (2008). By contrast, for ADHD patients, there was an increase in tau, but not in sigma. The characterization of ADHD by increased tau, but not sigma, is in accordance with previous studies although the effect size in the present study is comparatively smaller (as reviewed in Feige et al., 2013). Especially-slow responses that underlie tau have often been associated with lapses of attention (Leth-Steensen et al., 2000) which may reflect poor suppression of the default mode network (DMN) in ADHD patients (Feige et al., 2013; Sonuga-Barke \& Castellanos, 2007). More research is required to understand the meaning of elevated sigma in ASD+ patients, but previous work has linked sigma with different cognitive mechanisms such as sensory and perceptual attentional processing (Kieffaber et al., 2006), non-analytic and automatic (stimulus-related) processing (Balota \& Spieler, 1999), neural and motor (stimulus unrelated) processing (Blough, 1988) or retrieval processes (Penner-Wilger, LethSteensen \& Lefevre, 2002).

\subsection{Are the levels of ISV consistent across cognitively heterogeneous tasks in ASD patients?}

An important advantage of the present study was the systematic investigation of ISV across the cognitively heterogeneous task-battery which revealed that the pattern of highest levels of ISV in ASD+ patients followed by ADHD patients did not significantly differ across the divergent tasks. Findings of elevated ISV in ADHD patients across (Klein et al., 2006) or for (Kofler et al., 2013) cognitively heterogeneous tasks are in line with the literature, and our results provide additional evidence that such patterns are also present in ASD+ patients. The consistency of ISV-levels across the cognitively divergent tasks of WM, inhibition and temporal 
processing suggests it likely that increased ISV represents a fundamental abnormality in the ADHD-related groups rather than an outcome which is modulated by a specific cognitive process. The generalizability of elevated ISV may be studied as an important potential characteristic of the proposed trans-diagnostic phenotype for ADHD (Karalunas et al., 2014).

4.3 Are deficits related to the selected candidate cognitive endophenotypes of ADHD found in patients with $A S D$ ?

The increase in WM load did not differentiate either of the "pure" disorders from controls. The unexpected lack of WM impairment in ADHD patients may be related to the relatively low complexity of the employed WM task. The increase in WM load produced a disproportionate decrease in tau and disproportionate increase in omission errors in ASD+ patients. We found a moderate positive correlation between tau (or particularly slow responses) and omission errors ( $r=.384)$, in line with the findings of Tarantino et al. (2013), suggesting that the two measures share an underlying process, possibly lapses of attention (Feige et al., 2013; Fassbender et al., 2009) which may be overall more frequent in ASD+ patients. With regard to the debate concerning the association of ISV and WM in ADHD patients a consensus remains to be found since the current result of a lack of disproportionate load-related increase in RTSD in ADHD patients concurs with some previous findings (Feige et al., 2013; Buzy et al., 2009), but contradicts other work that found a greater increase in ADHDrelated variability with increasing WM load (Klein et al., 2006) and with the suggestion that ADHD-related ISV may be secondary to underlying WM deficits (Kofler et al., 2014).

Groups did not differ on measures of inhibitory processing which may be due to poor reliability of the SST paradigm (Wöstmann et al., 2013). Additionally, ADHD patients made more incorrect responses and ASD+ patients made more omission errors following 'GO' signals which may reflect different strategies or test-taking attitudes between groups.

ADHD patients, but not ASD- patients, had overall higher temporal error due to overestimated short and underestimated long intervals. This pattern of temporal processing deficits is in line with previous ADHD reports (West et al., 2000) and also confirms results of Hurks \& Hendriksen (2011) who, in addition, reported that overestimation of short intervals was associated with higher impulsivity and underestimation of long intervals with attentional deficits. Since we found the same results in ASD+ patients as well, this pattern of temporal processing deficits, like elevated ISV, may reflect a trans-diagnostic marker of ADHD. That said, it is important 
to note that Principal Component Analyses (PCA) ran on temporal accuracy scores in the experimental groups separately, revealed a fairly clear and consistent structure with 1-4 sec intervals loading component 1 (loadings between .68 and .98 ) but not component 2 (loadings between -.09 and .22), and 8-16 sec intervals loading component 2 (loadings between .86 and .95 ) but not component 1 (loadings between .01 and .30). Consequently, temporal processing deficits, like elevated ISV, may exhibit a structure of related, but only partially redundant components.

\subsection{Are deficits in comorbid patients explained by additive effects of the pure disorders?}

ASD+ patients had highest levels of ISV, temporal processing deficits, response slowing and made a higher number of omission errors; pointing to a more severe profile than either of the pure disorders. It is noteworthy that elevated sigma and mu and a higher number of omission errors for ASD+ patients in the NBT could not be explained by the additive influence of the pure disorders, suggesting that these may be unique markers for the comorbidity. For all other performance measures like SD of RTs and reproduced intervals, tau, incorrect responses, temporal processing measures and mean RTs, additive effects of the pure disorders are indicated for ASD+ patients. Also, the unique co-occurrence of increased ISV and response slowing in only ASD+ patients may arise from additive effects of two uniquely characterized (pure) disorders whereby increased ISV being more characteristic to ADHD symptomatology and response slowing being more characteristic to ASD symptomatology.

The current findings suggest that comorbidity is partly explained as an additive co-occurrence of ASDand ADHD but the presence of some distinct markers point to a potentially exclusive profile for ASD+; thus contesting the suggestion of Craig et al. (2016), who reviewed executive functioning (EF) profiles in ADHD and ASD and concluded that comorbidity is likely additive rather than a separate condition with unique impairments. Recent studies that employed similar statistical methods as the current work found that comorbidity is generally additive and characterized by unique deficits of the pure disorders (Tye, Asherson et al., 2014; Tye, Battaglia et al., 2014; Shephard et al., 2018), but a few non-additive patterns were found for reaction time variability (Tye, Asherson et al., 2014; Tye et al., 2016) and event-related potentials related to response preparation (Tye, Asherson et al., 2014) and social cognition (Tye, Battaglia et al., 2014). The presence of non-additive patterns points to unique processing or additional factors underlying the cognitive performance in comorbid patients. Previous studies found that co-occurring symptoms of ASD and ADHD are explained by overlapping genetic 
factors of the pure disorders (Arnett et al., 2017) but also distinct gene-environmental influences (Ronald et al., 2008; Rommelse, Franke et al., 2010; Kröger et al., 2011). More research is warranted to better understand the status of comorbid ADHD and ASD.

Of the measures examined in the current study, ISV, with largest effect sizes, was most sensitive to group differences. Although the present study is limited by the exclusive use of computer testing for ISV (and cognitive) measures, similar results can be expected in real-world settings since children with ADHD are more variable in visually attending to required stimuli in the classroom setting as well (Kofler et al., 2008). Based on our findings of elevated ISV in patients with symptoms of ADHD, it is possible that ISV serves as a useful, quantifiable construct for the identification and segregation of dimensionally-homogeneous subgroups which could facilitate more precise identification of underlying aetiological factors and consequently inform future clinical treatment approaches.

Conflict of interests: S.B. is a part of the advisory board for Autism Spectrum Disorder, Roche and has received support for conference participation from Shire, Lilly and Medice. 
Table 1 - Demographic and clinical characteristics with main effect of GROUP and pattern of pairwise comparisons

MALE\%

AGE

IQ

CBCL TOTAL

DISYPS-INATTENTION

DISYPS-HYPERACTIVITY

DISYPS-IMPULSIVITY

DISYPS-TOTAL SCORE

SRS-SOCIAL COGNITION

SRS-SOCIAL COMMUNICATION

SRS-SOCIAL MOTIVATION

SRS-AUTISTIC MANNERISMS

SRS TOTAL SCORE
SRS-SOCIAL AWARENESS

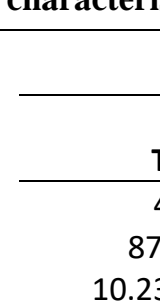

$10.23 \pm 1.58$

$107.20 \pm 18.33$

$49.70 \pm 9.25$

$-$

$\begin{array}{ll} & 0.80 \pm 0.69 \\ - & 1.38 \pm 0.79\end{array}$

$1.38 \pm 0.79$

$1.31 \pm 0.58$

$45.88 \pm 9.25$

$46.88 \pm 7.74$

$44.50 \pm 8.59$

$47.58 \pm 10.54$

$49.92 \pm 5.90$

$42.73 \pm 10.59$

$62.42 \pm 10.54$
$61.92 \pm 11.03$

$64.20 \pm 12.55$

$59.77 \pm 12.40$

$63.12 \pm 9.82$

$63.52 \pm 11.56$

Descriptive statistics

Note: CBCL: Child Behaviour Checklist; DISYPS: Germa p-values: n.s. $>.05 ; *<=.05 ; * *<=.01 ; * * *<=.001$. 
Table 2 - Descriptive statistics of performance measures

\begin{tabular}{|c|c|c|c|c|}
\hline & Controls & ADHD & ASD+ & ASD- \\
\hline \multicolumn{5}{|l|}{ Measures of ISV } \\
\hline NBT RTSD & $111.5 \pm 30.4$ & $138 \pm 45.6$ & $188.8 \pm 60.08$ & $124.4 \pm 47.8$ \\
\hline SST RTSD & $140.1 \pm 50.8$ & $156.4 \pm 51.7$ & $197.3 \pm 66.80$ & $149.3 \pm 52.7$ \\
\hline TRT SD of reproduced intervals & $0.29 \pm 0.14$ & $0.38 \pm 0.21$ & $0.45 \pm 0.26$ & $0.30 \pm 0.16$ \\
\hline NBT Sigma & $66.2 \pm 25.3$ & $71.8 \pm 35.6$ & $102.9 \pm 65.2$ & $64.4 \pm 23.2$ \\
\hline SST Sigma & $91.9 \pm 56.4$ & $91 \pm 44.3$ & $119 \pm 75.7$ & $77.2 \pm 39.2$ \\
\hline NBT Tau & $83.8 \pm 36.2$ & $113.1 \pm 56.3$ & $148 \pm 71.8$ & $104.1 \pm 52.1$ \\
\hline SST Tau & $95 \pm 50.4$ & $116.6 \pm 57.5$ & $141 \pm 87.4$ & $126.8 \pm 52.8$ \\
\hline Task-wise z-transformed ISV & $-0.37 \pm 0.44$ & $0.07 \pm 0.71$ & $0.80 \pm 0.95$ & $-0.16 \pm 0.74$ \\
\hline \multicolumn{5}{|l|}{$\begin{array}{l}\text { Measures of cognitive performance } \\
\text { NBT of WM }\end{array}$} \\
\hline Incorrect responses & $20.6 \pm 13$ & $27.6 \pm 13.9$ & $27.3 \pm 13.7$ & $23.8 \pm 13.1$ \\
\hline Omission errors & $2.8 \pm 4.9$ & $4.9 \pm 7.9$ & $16.8 \pm 23.1$ & $4.4 \pm 7.9$ \\
\hline Mean Reaction Time & $491.4 \pm 76.8$ & $504.4 \pm 83.6$ & $605.7 \pm 169.3$ & $497.4 \pm 116.9$ \\
\hline Mu & $407.6 \pm 69.5$ & $391.4 \pm 76.8$ & $463.7 \pm 163$ & $393.4 \pm 82.8$ \\
\hline \multicolumn{5}{|l|}{ SST of inhibition } \\
\hline Inhibition accuracy & $54.4 \pm 6.2$ & $51.7 \pm 2.9$ & $55.3 \pm 9$ & $52.2 \pm 2.7$ \\
\hline Stop Signal Delay & $298.3 \pm 161.2$ & $222 \pm 108.1$ & $280.4 \pm 240.1$ & $218.3 \pm 103.3$ \\
\hline Stop Reaction Time & $479.3 \pm 115.2$ & $440.9 \pm 100.8$ & $538 \pm 193.7$ & $483.5 \pm 150$ \\
\hline Stop Signal Reaction Time & $89.4 \pm 45$ & $105.2 \pm 59.3$ & $113.3 \pm 88.4$ & $69.5 \pm 64.5$ \\
\hline Incorrect responses & $28.3 \pm 25$ & $45.3 \pm 26$ & $42.5 \pm 28.4$ & $40.1 \pm 30.1$ \\
\hline Omission errors & $10 \pm 12.3$ & $13.9 \pm 13.7$ & $26.1 \pm 21.9$ & $14.5 \pm 27.4$ \\
\hline Mean Reaction Time & $568.7 \pm 133.6$ & $546.2 \pm 110.9$ & $651.3 \pm 208.2$ & $552.9 \pm 119.8$ \\
\hline Mu & $473.7 \pm 135.5$ & $429.6 \pm 99.3$ & $510.4 \pm 217.9$ & $426.2 \pm 98.5$ \\
\hline \multicolumn{5}{|l|}{ TRT of temporal processing } \\
\hline Relativized Absolute Discrepancy & $0.28 \pm 0.12$ & $0.34 \pm 0.18$ & $0.40 \pm 0.20$ & $0.29 \pm 0.2$ \\
\hline Coefficient of accuracy & $0.93 \pm 0.22$ & $0.97 \pm 0.27$ & $0.97 \pm 0.29$ & $0.95 \pm 0.3$ \\
\hline
\end{tabular}


Table 3: Summary of main effect of GROUP and pairwise comparisons with effect sizes for SD measures

\begin{tabular}{|c|c|c|c|c|c|c|c|c|c|c|c|c|c|}
\hline & MAIN & \multicolumn{12}{|c|}{ PAIRWISE COMPARISONS } \\
\hline & \multirow{2}{*}{$\begin{array}{l}\text { GROUP } \\
F(3,114)\end{array}$} & \multicolumn{2}{|c|}{$\begin{array}{l}\text { ADHD vs. } \\
\text { CONTROLS }\end{array}$} & \multicolumn{2}{|c|}{$\begin{array}{l}\text { ASD- vs. } \\
\text { CONTROLS }\end{array}$} & \multicolumn{2}{|c|}{$\begin{array}{l}\text { ASD+ vs. } \\
\text { CONTROLS }\end{array}$} & \multicolumn{2}{|c|}{$\begin{array}{l}\text { ASD+ vs. } \\
\text { ADHD }\end{array}$} & \multicolumn{2}{|c|}{$\begin{array}{l}\text { ASD- vs. } \\
\text { ADHD }\end{array}$} & \multicolumn{2}{|c|}{$\begin{array}{c}\text { ASD+ vs. } \\
\text { ASD- }\end{array}$} \\
\hline & & $t(114)$ & $d$ & $t(114)$ & $d$ & $t(114)$ & $d$ & $t(114)$ & $d$ & $t(114)$ & $d$ & $t(114)$ & $d$ \\
\hline NBT RTSD & $15.58 * * *$ & $3.20 * *$ & .60 & 1.86 & .35 & $6.67 * * *$ & 1.25 & $4.12^{* * *}$ & 0.77 & -0.77 & -.14 & $4.22 * * *$ & .79 \\
\hline SST RTSD & $5.98 * * *$ & 2.06 & .39 & 1.56 & .29 & $4.10 * * *$ & .77 & 2.46 & 0.46 & -0.14 & -.03 & 2.25 & .42 \\
\hline TRT SD & $10.19 * * *$ & $3.80 * *$ & .71 & 1.15 & .22 & $4.92 * * *$ & .92 & 1.89 & 0.35 & -1.98 & -.37 & $3.30 * *$ & .62 \\
\hline
\end{tabular}

Note: Age and IQ are covariates. RTSD computed using residualised RTs for NBT and SST. TRT SD: standard deviation of reproduced intervals.

p-values: $*<=.05 ; * *<=.01 ; * * *<=.001$. 
Table 4 - Summary of main effect of diagnostic status (DS) and interaction effect of diagnostic statuses

\begin{tabular}{|c|c|c|c|c|c|c|}
\hline \multirow{3}{*}{ Measures of ISV } & \multicolumn{2}{|c|}{ ADHD-DS x ASD-DS } & \multicolumn{2}{|c|}{ ASD-DS } & \multicolumn{2}{|c|}{ ADHD-DS } \\
\hline & $F(114)$ & $p$ & $F(116)$ & $p$ & $F(116)$ & $p$ \\
\hline & \\
\hline NBT RTSD & 2.84 & .095 & 14.26 & $<.001$ & 21.41 & $<.001$ \\
\hline SST RTSD & 0.48 & .490 & 7.56 & .007 & 8.27 & .005 \\
\hline TRT SD of reproduced intervals & 0.32 & .575 & 3.57 & .061 & 24.40 & $<.001$ \\
\hline NBT Sigma & 4.74 & .032 & 12.29 & $<.001$ & 10.61 & .002 \\
\hline SST Sigma & 1.73 & .191 & 2.10 & .151 & 1.28 & .261 \\
\hline NBT Tau & 0.00 & .995 & 5.05 & .027 & 7.30 & .008 \\
\hline SST Tau & 0.89 & .347 & 2.70 & .103 & 4.57 & .035 \\
\hline Task-wise z-transformed ISV & 2.57 & .112 & 13.32 & $<.001$ & 20.38 & $<.001$ \\
\hline \multicolumn{7}{|l|}{$\begin{array}{l}\text { Measures of cognitive performance } \\
\text { NBT of WM }\end{array}$} \\
\hline Incorrect responses & 1.37 & .244 & 0.44 & .506 & 6.39 & .013 \\
\hline Omission errors & 5.78 & .018 & 12.38 & $<.001$ & 7.28 & .008 \\
\hline Mean Reaction Time & 2.90 & .091 & 8.90 & .004 & 5.19 & .025 \\
\hline $\mathrm{Mu}$ & 3.96 & .049 & 4.96 & .028 & 1.62 & .206 \\
\hline \multicolumn{7}{|l|}{ SST of inhibition } \\
\hline Stop Signal Delay & 4.87 & .029 & 0.15 & .696 & 1.27 & .263 \\
\hline Stop Reaction Time & 1.43 & .234 & 4.92 & .029 & 0.75 & .388 \\
\hline Stop Signal Reaction Time & 1.10 & .297 & 0.31 & .576 & 4.90 & .029 \\
\hline Incorrect responses & 3.37 & .069 & 0.81 & .371 & 5.12 & .026 \\
\hline Omission errors & 0.33 & .565 & 6.34 & .013 & 2.59 & .110 \\
\hline Mean Reaction Time & 2.77 & .099 & 3.45 & .066 & 0.05 & .823 \\
\hline Mu & 3.86 & .052 & 0.44 & .507 & 0.22 & .638 \\
\hline \multicolumn{7}{|l|}{ TRT of temporal processing } \\
\hline Relativized Absolute Discrepancy & 0.00 & .983 & 2.78 & .098 & 10.07 & .002 \\
\hline Coefficient of accuracy & 0.16 & .686 & 0.05 & .822 & 1.24 & .267 \\
\hline
\end{tabular}

Note: Age and IQ are covariates. ISV measures computed using residualised RTs. DS: Diagnostic Status. ASDDS: ASD-/ASD+ vs. Controls/ADHD; ADHD-DS: ADHD/ASD+ vs. Controls/ASD-. 


\section{References}

Achenbach T. M., \& Rescorla L. A. (2001). Child Behaviour Checklist. Manual for the ASEBA School-Age Forms and Profiles. Burlington, VT: University of Vermont, Research Center for Children, Youth, and Families. M. Döpfner, J. Plück, C. Kinnen, für die Arbeitsgruppe Deutsche Child Behavior Checklist. Hogrefe, 2014.

Adamo, N., Huo, L., Adelsberg, S., Petkova, E., Castellanos, F. X., \& Di Martino, A. (2014). Response time intra-subject variability: commonalities between children with autism spectrum disorders and children with ADHD. European Child \& Adolescent Psychiatry, 23(2), 69-79. doi:10.1007/s00787-013-0428-4

Alderson, R. M., Rapport, M. D., \& Kofler, M. J. (2007). Attention-deficit/hyperactivity disorder and behavioral inhibition: A meta-analytic review of the stop-signal paradigm. Journal of Abnormal Child Psychology, 35(5), 745-758. doi:10.1007/s10802-007-9131-6

American Psychiatric Association. (2013). Diagnostic and statistical manual of mental disorders (5th ed.). American Psychiatric Association. Washington, DC: Author.

Antonini, T. N., Narad, M. E., Landberg, J. M., \& Epstein, J. N. (2013). Behavioral correlates of reaction time variability in children with and without ADHD. Neuropsychology, 27(2), 201-209. doi:10.1037/a0032071.

Arnett, A. B., Cairney, B. E., Wallace, A. S., Gerdts, J., Turner, T. N., Eichler, E. E., \& Bernier, R. A. (2017). Comorbid symptoms of inattention, autism, and executive cognition in youth with putative genetic risk. Journal of Child Psychology and Psychiatry. doi:10.1111/jcpp.12815

Balota, D. A., \& Spieler, D. H. (1999). Word frequency, repetition, and lexicality effects in word recognition tasks: Beyond measures of central tendency. Journal of Experimental Psychology: General, 128(1), 32-55. doi:10.1037/0096-3445.128.1.32

Bhatara, A., Babikian, T., Laugeson, E., Tachdjian, R., \& Sininger, Y. S. (2013). Impaired timing and frequency discrimination in high-functioning autism spectrum disorders. Journal of Autism and Developmental Disorders, 43(10), 2312-2328. doi:10.1007/s10803-013-1778-y

Bidwell, L. C., Willcutt, E. G., DeFries, J. C., \& Pennington, B. F. (2007). Testing for Neuropsychological Endophenotypes in Siblings Discordant for Attention-Deficit/Hyperactivity Disorder. Biological Psychiatry, 62(9), 991-998. doi:10.1016/j.biopsych.2007.04.003

Biscaldi, M., Bednorz, N., Weissbrodt, K., Saville, C. W. N., Feige, B., Bender, S., \& Klein, C. (2016). Cognitive endophenotypes of attention deficit / hyperactivity disorder and intra-subject variability in patients with autism spectrum disorder. Biological Psychology, 118, 25-34. doi:10.1016/j.biopsycho.2016.04.064

Blough, D. S. (1988). Quantitative relations between visual search speed and target-distractor similarity. Perception \& Psychophysics, 43(1), 57-71. doi:10.3758/BF03208974

Bölte, S., \& Poustka, F. (2007). Skala zur erfassung sozialer reaktivität-Dimensionale autismus-diagnostik. german version of the social responsiveness scale (SRS) by John N. Constantino und Christian P. Gruber. Bern: Huber.

Bölte, S., Rühl, D., Schmötzer, G., \& Poustka, F. (2005). Diagnostisches interview für autismus-revidiert. Deutsche fassung des autism diagnostic interview_revised (ADI-R) by Michael Rutter, Ann Le Couteur und Catherine Lord. Bern: Huber.

Buzy, W. M., Medoff, D. R., \& Schweitzer, J. B. (2009). Intra-Individual Variability among children with ADHD on a Working Memory Task: An ex-Gaussian approach. Child Neuropsychology, 15(5), 441-459. doi:10.1080/09297040802646991.

Castellanos, F. X., \& Tannock, R. (2002). Neuroscience of attention-deficit/hyperactivity disorder: the search for endophenotypes. Nature Reviews. Neuroscience, 3(8), 617-28. doi:10.1038/nrn896 
Castellanos, F. X., Sonuga-Barke, E. J. S., Scheres, A., Di Martino, A., Hyde, C.\& Walters, J. R. (2005). Varieties of Attention-Deficit/Hyperactivity Disorder-Related Intra- Individual Variability. Biological Psychiatry, 57(11), 1416-1423. doi:10.1016/j.biopsych.2004.12.005

Corbett, B. a., Constantine, L. J., Hendren, R., Rocke, D., \& Ozonoff, S. (2009). Examining executive functioning in children with autism spectrum disorder, attention deficit hyperactivity disorder and typical development. Psychiatry Research, 166(2-3), 210-222. doi:10.1016/j.psychres.2008.02.005.

Cousineau, D., Brown, S., \& Heathcote, A. (2004). Fitting distributions using maximum likelihood: methods and packages. Behavior Research Methods, Instruments, \& Computers, 36(4), 742-756.

Craig, F., Margari, F., Legrottaglie, A. R., Palumbi, R., de Giambattista, C., \& Margari, L. (2016). A review of executive function deficits in autism spectrum disorder and attention-deficit/hyperactivity disorder. Neuropsychiatric Disease and Treatment, 12, 1191-1202. doi:10.2147/NDT.S104620

Dennis, M., Francis, D. J., Cirino, P. T., Schachar, R., Barnes, M. A., \& Fletcher, J. M. J. M. (2009). Why IQ is not a covariate in cognitive studies of neurodevelopmental disorders. Journal of the International Neuropsychological Society, 15(3), 331-343. doi:10.1017/S1355617709090481.

Devito, E. E., Blackwell, A. D., Clark, L., Kent, L., Dezsery, A. M., Turner, D. C., ... Sahakian, B. J. (2009). Methylphenidate improves response inhibition but not reflection-impulsivity in children with attention deficit hyperactivity disorder (ADHD). Psychopharmacology, 202(1-3), 531-539. doi:10.1007/s00213008-1337-y

Döpfner, M., Görtz-Dorten, A., Lehmkuhl, G., Breuer, D., \& Goletz, H. (2008). Diagnostik-system für psychische Störungen nach ICD-10 und DSM-IV für kinder und jugendliche (DISYPS-II, FBB-ADHS). Bern: Huber.

Falter, C. M., Noreika, V., Wearden, J. H., \& Bailey, A. J. (2012). More consistent, yet less sensitive: interval timing in autism spectrum disorders. Quarterly Journal of Experimental Psychology, 65(11), 2093-2107. doi:10.1080/17470218.2012.690770

Fassbender, C., Zhang, H., Buzy, W. M., Cortes, C. R., Mizuiri, D., Beckett, L., \& Schweitzer, J. B. (2009). A lack of default network suppression is linked to increased distractibility in ADHD. Brain Research, 1273, 114-28. doi:10.1016/j.brainres.2009.02.070

Feige, B., Biscaldi, M., Saville, C. W. N., Kluckert, C., Bender, S., Ebner-Priemer, U., ... Klein, C. (2013). On the Temporal Characteristics of Performance Variability in Attention Deficit Hyperactivity Disorder (ADHD). PLoS ONE, 8(10), e69674. doi:10.1371/journal.pone.0069674

Fiske D., \& Rice L. (1955). Intra-Individual Response Variability. Psychological Bulletin, 52(3), 217-250.

Flehming, H. C., Steinborn, M., Langner, R., Scholz, A., \& Westhoff, K. (2007). Assessing intraindividual variability in sustained attention: reliability, relation to speed and accuracy, and practice effects. Psychology Science, 49(2), 132-149.

Geurts, H. M., Grasman, R. P. P. P., Verté, S., Oosterlaan, J., Roeyers, H., van Kammen, S. M., \& Sergeant, J. A. (2008). Intra-individual variability in ADHD, autism spectrum disorders and Tourette's syndrome. Neuropsychologia, 46(13), 3030-41. doi:10.1016/j.neuropsychologia.2008.06.013

Gil, S., Chambres, P., Hyvert, C., Fanget, M., \& Droit-Volet, S. (2012). Children with Autism Spectrum Disorders Have "The Working Raw Material” for Time Perception. PLoS ONE, 7(11), 1-10. doi:10.1371/journal.pone.0049116

Goldberg, M. C., Mostofsky, S. H., Cutting, L. E., Mahone, E. M., Astor, B. C., Denckla, M. B., \& Landa, R. J. (2005). Subtle executive impairment in children with autism and children with ADHD. Journal of Autism and Developmental Disorders, 35(3), 279-293. doi:10.1007/s10803-005-3291-4 
Gottesman, I. I., \& Gould, T. D. (2003). The endophenotype concept in psychiatry: Etymology and strategic intentions. American Journal of Psychiatry, 160(4), 636-645. doi:10.1176/appi.ajp.160.4.636

Happé, F., Booth, R., Charlton, R., \& Hughes, C. (2006). Executive function deficits in autism spectrum disorders and attention-deficit/hyperactivity disorder: Examining profiles across domains and ages. Brain and Cognition, 61(1), 25-39. doi:10.1016/j.bandc.2006.03.004

Heiser, P., Frey, J., Smidt, J., Sommerlad, C., Wehmeier, P. M., Hebebrand, J., \& Remschmidt, H. (2004). Objective measurement of hyperactivity, impulsivity, and inattention in children with hyperkinetic disorders before and after treatment with methylphenidate. European Child and Adolescent Psychiatry, 13(2), 100-104. doi:10.1007/s00787-004-0365-3

Henriquez-Henriquez, M. P., Billeke, P., Henriquez, H., Zamorano, F. J., Rothhammer, F., \& Aboitiz, F. (2015). Intra-individual response variability assessed by ex-Gaussian analysis may be a new endophenotype for attention-deficit/hyperactivity disorder. Frontiers in Psychiatry, 6, 1-8. doi:10.3389/fpsyt.2014.00197

Hervey, A. S., Epstein, J. N., Curry, J. F., Tonev, S., Eugene Arnold, L., Keith Conners, C., ... Hechtman, L. (2006). Reaction time distribution analysis of neuropsychological performance in an ADHD sample. Child Neuropsychology, 12(2), 125-140. doi:10.1080/09297040500499081

Hurks, P. P. M., \& Hendriksen, J. G. M. (2011). Retrospective and prospective time deficits in childhood ADHD: The effects of task modality, duration, and symptom dimensions. Child Neuropsychology, 17(1), 34-50. doi:10.1080/09297049.2010.514403

Karalunas, S. L., Geurts, H. M., Konrad, K., Bender, S., \& Nigg, J. T. (2014). Annual Research Review : Reaction time variability in ADHD and autism spectrum disorders : measurement and mechanisms of a proposed trans-diagnostic phenotype. Journal of Child Psychology and Psychiatry, 55(6), 685-710. doi:10.1111/jcpp. 12217

Kasper, L. J., Alderson, R. M., \& Hudec, K. L. (2012). Moderators of working memory deficits in children with attention-deficit/hyperactivity disorder (ADHD): A meta-analytic review. Clinical Psychology Review, 32(7), 605-617. doi:10.1016/j.cpr.2012.07.001

Kaufman, J., Birmaher, B., Brent, D., Rao, U., \& Ryan, N. (2001). Kiddie-Sads-Present and lifetime version (KSADS-PL) version 1.0 of october 1996. German adaptation by K-SADS-Arbeitsgruppe. Berlin, Bern, Köln, Frankfurt/M., Hamburg,Jena, Mannheim, Rostock: K-SADS-Arbeitsgruppe.

Kieffaber, P. D., Kappenman, E. S., Bodkins, M., Shekhar, A., O’Donnell, B. F., \& Hetrick, W. P. (2006). Switch and maintenance of task set in schizophrenia. Schizophrenia Research, 84(2-3), 345-58. doi:10.1016/j.schres.2006.01.022

Klein, C., Wendling, K., Huettner, P., Ruder, H., \& Peper, M. (2006). Intra-subject variability in attention-deficit hyperactivity disorder. Biological Psychiatry, 60(10), 1088-97. doi:10.1016/j.biopsych.2006.04.003

Kofler, M. J., Alderson, R. M., Raiker, J. S., Bolden, J., Sarver, D. E., \& Rapport, M. D. (2014). Working memory and intraindividual variability as neurocognitive indicators in ADHD: Examining competing model predictions. Neuropsychology, 28(3), 459-471. doi:10.1037/neu0000050

Kofler, M. J., Rapport, M. D., \& Alderson, M.R. (2008). Quantifying ADHD classroom inattentiveness, its moderators, and variability: A meta-analytic review. Journal of Child Psychology and Psychiatry, 49(1), 59-69. doi:10.1111/j.1469-7610.2007.01809.x

Kofler, M. J., Rapport, M. D., Sarver, D. E., Raiker, J. S., Orban, S. A., Friedman, L. M., \& Kolomeyer, E. G. (2013). Reaction time variability in ADHD: a meta-analytic review of 319 studies. Clinical Psychology Review, 33(6), 795-811. doi:10.1016/j.cpr.2013.06.001 
Kröger, A., Hänig, S., Seitz, C., Palmason, H., Meyer, J., \& Freitag, C. M. (2011). Risk factors of autistic symptoms in children with ADHD. European Child and Adolescent Psychiatry, 20(11-12), 561-570. doi:10.1007/s00787-011-0221-1

Kuntsi, J., \& Klein, C. (2012). Intraindividual Variability in ADHD and Its Implications for Research of Causal Links. Current Topics in Behavioral Neurosciences: Behavioral Neurobiology of ADHD and Its Treatment, 67-91. doi: 10.1007/7854_2011_145

Kuntsi, J., \& Stevenson, J. (2001). Psychological mechanisms in hyperactivity: II. The role of genetic factors. $J$ Child Psychol Psychiatry, 42(2), 211-219.

Lee, S.-H., Song, D.-H., Kim, B.-N., Joung, Y. S., Ha, E. H., Cheon, K.-A., ... Shin, D.-W. (2009). Variability of Response Time as a Predictor of Methylphenidate Treatment Response in Korean Children with Attention Deficit Hyperactivity Disorder. Yonsei Medical Journal, 50(5), 650. doi:10.3349/ymj.2009.50.5.650

Leth-Steensen, C., King Elbaz, Z., \& Douglas, V. I. (2000). Mean response times, variability, and skew in the responding of ADHD children: a response time distributional approach. Acta Psychologica, 104(2), 167190. doi:10.1016/S0001-6918(00)00019-6

Lijffijt, M., Leon, J., Verbaten, M. N., \& van Engeland, H. (2005). A Meta-Analytic Review of Stopping Performance in Attention-Deficit/Hyperactivity Disorder: Deficient Inhibitory Motor Control? Journal of Abnormal Psychology, 114(2), 216-222. doi:10.1037/0021-843X.114.2.216

Lin, H. Y., Hwang-Gu, S. L., \& Gau, S. S. F. (2015). Intra-individual reaction time variability based on exGaussian distribution as a potential endophenotype for attention-deficit/hyperactivity disorder. Acta Psychiatrica Scandinavica, 39-50. doi:10.1111/acps.12393

Lundervold, a. J., Stickert, M., Hysing, M., Sorensen, L., Gillberg, C., \& Posserud, M.-B. (2012). Attention Deficits in Children With Combined Autism and ADHD: A CPT Study. Journal of Attention Disorders. doi:10.1177/1087054712453168

Mahone, E. M., Powell, S. K., Loftis, C. W., Goldberg, M. C., Denckla, M. B., \& Mostofsky, S. H. (2006). Motor persistence and inhibition in autism and ADHD. Journal of the International Neuropsychological Society : JINS, 12(5), 622-631. doi:10.1017/S1355617706060814

Martinussen, R., Hayden, J., Hogg-Johnson, S., \& Tannock, R. (2005). A Meta-Analysis of Working Memory Impairments in Children With Attention-Deficit/Hyperactivity Disorder. Journal of the American Academy of Child \& Adolescent Psychiatry, 44(4), 377-384. doi:10.1097/01.chi.0000153228.72591.73

Nigg, J. T., Blaskey, L. G., Stawicki, J. A., \& Sachek, J. (2004). Evaluating the Endophenotype Model of ADHD Neuropsychological Deficit: Results for Parents and Siblings of Children With ADHD Combined and Inattentive Subtypes. Journal of Abnormal Psychology, 113(4), 614-625. doi:10.1037/0021843X.113.4.614

Nolen-Hoeksema, S., \& Watkins, E.R. (2011). A heuristic for developing transdiagnostic models of psychopathology: Explaining multifinality and divergent trajectories. Perspectives on Psychological Science, 6, 589-609.

Noreika, V., Falter, C. M., \& Rubia, K. (2013). Timing deficits in attention-deficit/hyperactivity disorder (ADHD): evidence from neurocognitive and neuroimaging studies. Neuropsychologia, 51(2), 235-66. doi:10.1016/j.neuropsychologia.2012.09.036

Penner-Wilger, M., Leth-Steensen, C., \& LeFevre, J.-A. (2002). Decomposing the problem-size effect: A comparison of response time distribution across cultures. Memory and Cognition, 30(7), 1160-1167.

Pinheiro, J., Bates, D., DebRoy, S., Sarkar, D. \& R Core Team (2015). Nlme:Linear and Non-linear Mixed Effects Models. R package version 3.1-120. http://CRAN.R-project.org/packages=nlme 
R Core Team (2013). R: A language and environment for statistical computing. R foundation for Statistical Computing, Vienna, Austria. URL http://www.R-project.org/.

Raven, J. C., \& Horn, R. (2009). Standard progressive matrices (SPM). (German version according to J.C. Raven). Frankfurt: Pearson Assessment.

Reiersen, A. M., \& Todd, R. D. (2008). Co-occurrence of ADHD and autism spectrum disorders: phenomenology and treatment. Expert Review of Neurotherapeutics, 8(4), 657-669. doi:10.1586/14737175.8.4.657

Rommelse, N. N. J., Franke, B., Geurts, H., Hartman, C. A. \& Buitelaar, J. K. (2010). Shared heritability of attention-deficit/hyperactivity disorder and autism spectrum disorder, European Child \& Adolescent Psychiatry, 19, 281-295. doi:10.1007/s00787-010-0092-x

Rommelse, N. N. J., Geurts, H. M., Franke, B., Buitelaar, J. K., \& Hartman, C. a. (2011). A review on cognitive and brain endophenotypes that may be common in autism spectrum disorder and attentiondeficit/hyperactivity disorder and facilitate the search for pleiotropic genes. Neuroscience and Biobehavioral Reviews, 35(6), 1363-96. doi:10.1016/j.neubiorev.2011.02.015

Rommelse, N. N. J., Oosterlaan, J., Buitelaar, J., Faraone, S. V., \& Sergeant, J. A. (2007). Time Reproduction in Children With ADHD and Their Nonaffected Siblings. Journal of the American Academy of Child \& Adolescent Psychiatry, 46(5), 582-590. doi:10.1097/CHI.0b013e3180335af7

Ronald, A., Simonoff, E., Kuntsi, J., Asherson, P., \& Plomin, R. (2008). Evidence for overlapping genetic influences on autistic and ADHD behaviours in a community twin sample. Journal of Child Psychology and Psychiatry, 49(5), 535-542. doi:10.1111/j.1469-7610.2007.01857.x

Rucklidge, J. J., \& Tannock, R. (2002). Neuropsychological profiles of adolescents with ADHD: effects of reading difficulties and gender. Journal of Child Psychology and Psychiatry, 43(8), 988-1003. doi:10.1111/1469-7610.00227

Rühl, D., Bölte, S., Feineis-Matthews, S., \& Poustka, F. (2004). Diagnostische beobachtungsskala für autistische Störungen. German version of the autism diagnostic observation schedule (ADOS) by Lord, C., Rutter, M., Dilavore, P.C., and Risi, S. Bern: Huber.

Saville, C. W. N., Pawling, R., Trullinger, M., Daley, D., Intriligator, J., \& Klein, C. (2011). On the stability of instability: Optimising the reliability of intra-subject variability of reaction times. Personality and Individual Differences, 51(2), 148-153. doi:10.1016/j.paid.2011.03.034

Saville, C. W. N., Shikhare, S., Iyengar, S., Daley, D., Intriligator, J., Boehm, S. G., ... Klein, C. (2012). Is reaction time variability consistent across sensory modalities? Insights from latent variable analysis of single-trial P3b latencies. Biological Psychology, 91(2), 275-82. doi:10.1016/j.biopsycho.2012.07.006

Schneider,W., Eschman, A., \& Zuccolotto, A. (2002). E-Prime: User's guide. Pittsburgh, PA: Psychological Software Tools.

Shephard, E., Tye, C., Ashwood, K. L., Azadi, B., Asherson, P., Bolton, P. F., \& McLoughlin, G. (2018). Resting-State Neurophysiological Activity Patterns in Young People with ASD, ADHD, and ASD + ADHD. Journal of Autism and Developmental Disorders, 48(1),110-122. doi:10.1007/s10803-017-3300-4

Sinzig, J., Morsch, D., Bruning, N., Schmidt, M. H., \& Lehmkuhl, G. (2008). Inhibition, flexibility, working memory and planning in autism spectrum disorders with and without comorbid ADHD-symptoms. Child and Adolescent Psychiatry and Mental Health, 2, 4. doi:10.1186/1753-2000-2-4

Sinzig, J., Walter, D., \& Doepfner, M. (2009). Attention deficit/hyperactivity disorder in children and adolescents with autism spectrum disorder: symptom or syndrome? Journal of Attention Disorders, 13(2), 117-126. doi:10.1177/1087054708326261 
Sonuga-Barke, E. J. S., \& Castellanos, F. X. (2007). Spontaneous attentional fluctuations in impaired states and pathological conditions: A neurobiological hypothesis. Neuroscience and Biobehavioral Reviews, 31, 977986. doi:10.1016/j.neubiorev.2007.02.005

Sowerby, P., Seal, S., \& Tripp, G. (2011). Working memory deficits in ADHD: the contribution of age, learning/language difficulties, and task parameters. Journal of Attention Disorders, 15(6), 461-472. doi:10.1177/1087054710370674

Stasinopoulos D.M., Rigby R.A. (2007) Generalized Additive Models for Location Scale and Shape (GAMLSS) in R. J Stat Softw 23: 1-46.

Suskauer, S. J., Simmonds, D. J., Caffo, B. S., Denckla, M. B., Pekar, J. J., \& Mostofsky, S. H. (2008). fMRI of intrasubject variability in ADHD: anomalous premotor activity with prefrontal compensation. Journal of the American Academy of Child and Adolescent Psychiatry, 47(10), 1141-50. doi:10.1097/CHI.0b013e3181825b1f

Tamm, L., Narad, M. E., Antonini, T. N., O’Brien, K. M., Hawk, L. W., \& Epstein, J. N. (2012). Reaction Time Variability in ADHD: A Review. Neurotherapeutics, 9(3), 500-508. doi:10.1007/s13311-012-0138-5

Tarantino, V., Cutini, S., Mogentale, C., \& Bisiacchi, P. S. (2013). Time-on-task in children with ADHD: an exGaussian analysis. Journal of the International Neuropsychological Society : JINS, 19(7), 820-8. doi: $10.1017 / \mathrm{S} 1355617713000623$

Teicher, M. H., Lowen, S. B., Polcari, A., Foley, M., \& McGreenery, C. E. (2004). Novel Strategy for the Analysis of CPT Data Provides New Insight into the Effects of Methylphenidate on Attentional States in Children with ADHD. Journal of Child and Adolescent Psychopharmacology, 14(2), 219-232. doi:10.1089/1044546041648995

Toplak, M. E., Dockstader, C., \& Tannock, R. (2006). Temporal information processing in ADHD: Findings to date and new methods. Journal of Neuroscience Methods, 151(1), 15-29. doi:10.1016/j.jneumeth.2005.09.018

Tye, C., Asherson, P., Ashwood, K. L., Azadi, B., Bolton, P. and McLoughlin G.(2014). Attention and inhibition in children with ASD, ADHD and co-morbid ASD + ADHD: an event-related potential study. Psychological Medicine, 44, pp 1101-1116. doi:10.1017/S0033291713001049.

Tye, C., Battaglia, M., Bertoletti, E., Ashwood, K. L., Azadi, B., Asherson, P., ... McLoughlin, G. (2014). Altered neurophysiological responses to emotional faces discriminate children with ASD, ADHD and ASD + ADHD. Biological Psychology, 103, 125-134. doi:10.1016/j.biopsycho.2014.08.013

Tye, C., Johnson K., Kelly, S.P., Asherson, P., Kuntsi, J., Ashwood, K.L., Azadi, B., Bolton, P. \& McLoughin G. (2016). Response time variability under slow and fast-incentive conditions in children with ASD, ADHD and ASD+ADHD. Journal of Child Psychology and Psychiatry. doi:10.1111/jcpp.12608

van Steijn, D. J., Richards, J. S., Oerlemans, A. M., de Ruiter, S. W., van Aken, M. A. G., Franke, B., et al. (2012). The co-occurrence of autism spectrum disorder and attention-deficit/hyperactivity disorder symptoms in parents of children with ASD or ASD with ADHD. Journal of Child Psychology and Psychiatry, 53, 954-963.

Verté, S., Geurts, H. M., Roeyers, H., Oosterlaan, J., \& Sergeant, J. A. (2006). The relationship of working memory, inhibition, and response variability in child psychopathology. Journal of Neuroscience Methods, 151(1), 5-14. doi:10.1016/j.jneumeth.2005.08.023

Wallace, G. L., \& Happé, F. (2008). Time perception in autism spectrum disorders. Research in Autism Spectrum Disorders, 2(3), 447-455. doi:10.1016/j.rasd.2007.09.005 
West, J., Douglas, G., Houghton, S., Lawrence, V., Whiting, K., \& Glasgow, K. (2000). Time perception in boys with attention-deficit/hyperactivity disorder according to time duration, distraction and mode of presentation. Child Neuropsychology, 6(4), 241-250. doi:10.1076/chin.6.4.241.3140

Wodka, E. L., Mahone, E. M., Blankner, J. G., Larson, J. C. G., Fotedar, S., Denckla, M. B., \& Mostofsky, S. H. (2007). Evidence that response inhibition is a primary deficit in ADHD. Journal of Clinical and Experimental Neuropsychology, 29(4), 345-356. doi:10.1080/13803390600678046

Wöstmann, N. M., Aichert, D. S., Costa, A., Rubia, K., Möller, H. J., \& Ettinger, U. (2013). Reliability and plasticity of response inhibition and interference control. Brain and Cognition, 81(1), 82-94. doi:10.1016/j.bandc.2012.09.010 